Alexandra Jaffe*

\title{
Poeticizing the economy: The Corsican language in a nexus of pride and profit
}

https://doi.org/10.1515/multi-2018-0005

\begin{abstract}
This article explores the carefully managed semiotic complex found in the Corsican village of Pigna with respect to the themes of pride and profit in the valuation of minority languages. This complex includes the careful coordination of color, graphics, the use of the Corsican language, as well as high-tech soundscaping of place through QR codes that tie specific locales to Corsican music and multilingual texts. This display, labeled the "poeticizing of the economy" by a key social actor, is directed both at the many tourists who visit the village as well as Corsican visitors and locals. It is linked to an effort to embed Corsican linguistic and musical heritage in new practices that both create place and integrate tradition and modernity. On the one hand, these practices can be linked to discourses of both "pride" and "profit" (Duchêne and Heller 2012) attested in many minority language contexts. On the other hand, I argue that the Pigna esthetic indexes a shift in the framework for cultural and linguistic revitalization from one that emphasizes a return to past native speaker communicative practice to one that focuses on the collective agency and identity associated with style and stylization and "transactional," or situated authenticities.
\end{abstract}

Keywords: Corsica, Pigna, esthetics, stylization, poetic economy

\section{Introduction}

The Corsican village of Pigna stands out for its exceptionally intentional use of the Corsican language embedded in a tightly managed semiotic complex that is the nexus of the local tourist economy. On the surface, this intentional, stylized usage of Corsican looks like emblematic uses of minority languages attested in many different contexts. In this article, however, I argue that it reflects a more complex shift in linguistic and semiotic ideologies in the context of new European and global frameworks for understanding the value of minority languages and the markets are both invoked and created by new forms of language and representational practice. I explore what one of the central social actors in this village calls

*Corresponding author: Alexandra Jaffe, Linguistics and Anthropology, California State University Long Beach, Long Beach, CA, USA 
"the poeticization of the economy" and how it positions Corsican language and culture within models of "center" and "periphery" with reference to multiple scales, from the local to the national, to the European, to the global.

The analysis engages with several themes and bodies of literature related to language revitalization as it relates to commodification, authenticity, performance/ poetics and place. Ever since the publication of Duchêne and Heller's edited volume Language in Late Capitalism: Pride and Profit (2012), researchers have explored the tension between economic ("profit") and cultural/political ("pride") models of linguistic value. This has been particularly resonant in minority language contexts where discourses of language politics and revitalization have historically been centered around pride and cultural rights but, more recently, have increasingly adopted the language of the market to argue for the "added value" of minority language use (Jaffe 2007). In the commercial and tourist sphere, this added value is mobilized and embodied in a variety of linguistic practices, from the fetishizing of language used on tourist souvenirs (Kelly-Holmes 2014) to forms of linguistic landscaping that include emblematic visual uses of language in business or product names as forms of market differentiation and authentication (Heller et al. 2014) as well as the marketing of oral uses of minority language as a communicative or symbolic resource. The case of the Corsican village of Pigna illustrates how actors on the ground attune to the tension between pride and profit and attempt to create an alternative frame in which they can be integrated.

Language revitalization is almost invariably linked to place-based authenticities, and language-and representations of language-are intimately involved in the simultaneous production of place and authenticity (Johnstone 2010; Thurlow and Jaworski 2010; Pietikäinen and Kelly-Holmes 2011; Pietikäinen et al. 2016). In tourist contexts, this involves how fixed places are constructed as well as how people (both tourists and locals) move through and experience them. In Pigna, we will see how language and other semiotic tools are used to construct both place and tourists' trajectories through and interpretation of place and authenticity.

Here, we will be taking up the perspective that "Linguistic landscapes [...] have the potential to represent and to 'perform' language-ideological conditions, whether actual or imagined (Pietikäinen et al. 2016: 44). This trains the analytical focus on how the staging of places and pathways and tourist movements through them shape what they become for locals. This construction is an artful, reflexive staging of language. This focus on performance brings to the fore "how people use sets of semiotic resources to gradiently challenge and/or reinscribe normative ideologies and locally recognized, hierarchically organized identity categories" (Jaffe et al. 2015: 135). The data under analysis below in fact aligns with Thurlow and Jaworski (2010) preference for the term "semiotic," rather than just "linguistic" landscape, as it involves a wide variety of forms of signification. 
The meanings of these performances are shaped by a dynamic process of production and reception; they index, draw their meanings from, take up a position towards and potentially transform collective experiences of "center" and "periphery". For speakers of a minority language (Corsican) on an island "periphery" of France, these experiences include heteroglossia (Bakhtin 1992) and diversity itself, as well as dominant discourses and stereotypes about Corsica and Corsican that are inevitably brought into play in the way that the island is imagined and represented to and by tourists and potential tourists. The analysis addresses two categories of linguistic/semiotic performances of Corsican identity. In the first, dominant linguistic and cultural categories and boundaries remain more or less fixed, and languages are recruited primarily as market tools. In the second, these stance objects are creatively manipulated, recontextualized and re-entextualized (Bauman and Briggs 1990; Silverstein and Urban 1996). The result, to use a term coined by Toni Casalonga, a key cultural figure in Corsica who has been a driving force behind the successful marketing (to Corsicans and tourists) of musical and material culture in the village of Pigna, is the "poeticization of the economy" (Antonmarchi et al. 2010).

This poeticization recruits (often heterogeneous) language practices (rather than languages) in the service of exchanges which are economic, but create or presuppose relationships between languages, people, and places that blur center : periphery:: dominant : minority distinctions. In doing so, it offers the potential for social actors who are often subject to representations of themselves by others to exercise control over the way they, and their languages, are mediated and mediatized (Jaffe 2011) and participates in "transactional" forms of authentication (Pietikäinen et al. 2016).

Finally, I will also be addressing some tensions between the notion of the poeticization of the economy, which implies relations between producers and consumers that transcend the purely commercial-and other models of culture and commodification to which it's meant to be the antidote. We might call these "economization of poetry," where commercial interests and frames prevail in interactions between artistic producers and consumers.

\section{Background: Language, culture, tourism and the village of Pigna}

Corsica is a Mediterranean island that is part of France. The location of the village of Pigna is a privileged one on an island that is replete with natural beauty. It is situated on the West coast of the island of Corsica at an altitude of 
approximate 700 meters and overlooks a spectacular view of the beaches, and the town of Ile Rousse, that are about a 15- or 20-minute drive away. The Balagne region in which it is located is one of the most popular tourist destinations on the island because of the proximity of beach and mountains.

Corsica is positioned within France (where the bulk of its tourists come from) as both culturally and linguistically other. It has a history of both language shift from Corsican to French which began in the 1920s and a language revitalization movement that was born in the late sixties. The first phases of Corsican language activism focused primarily on cultural and political identities and rights, working within historical nationalist/linguistic discourses in which both language and people were posited as having authentic, essential qualities and identities that were the basis for cultural rights and authority. This was aligned with a monolingual language ideology that equated native speaker competence with personal cultural authenticity and balanced bilingualism with collective ethnolinguistic authenticity. Language planning was also concentrated primarily in the schools and other institutional contexts, where issues of purity and parity between French and Corsican prevailed. These rigid models of authenticity made it difficult for the many semi-speakers of Corsican to feel secure in their cultural identity and located the value and meaning of Corsican primarily as insider symbolic currency and a site of contestation with the French state and its linguistic and cultural dominance.

Beginning in the nineties, however, European models of "plurilingual citizenship" (Beacco and Byram 2003; Council of Europe 2001) began to make inroads in Corsican discourses about language and speakerhood. Using Corsican was reimagined as an element in a plurilingual repertoire that validated multiple types and levels of linguistic proficiency was an emblem of a superior openness of perspective and willingness to exchange with outsiders.

The village of Pigna was the home to many cultural actors who had taken part in the Rinascita-or 'renaissance' of Corsican culture and language of the seventies. Toni Casalonga, a central figure in that movement and in the village, had aligned himself early on with non-essentializing, monolingual/monocultural ideologies of Corsican. As president of the Cultural Commission of the Corsican Regional Assembly in 1989, he had drafted a document called Lingua Matria, in which he argued that while Corsican was no longer the "mother tongue" of Corsicans, it was still a legitimate emblem of collective culture and memory in a modern world, and deserved legal protection and promotion (CCECV 1989).

Casalonga was also one of the chief architects of the revitalization of Pigna and its marketing as both a cultural and musical hub and a privileged tourist destination. The village as it exists today is shaped in large part by his concept 
of the poeticization of the economy. This notion positions economic activity as integrated into locally meaningful linguistic and artistic practices. It also implies creative local control over the way that linguistic and cultural forms are mediated and staged.

The following text is the village website's account of this history.

In effect, it was in Pigna that the cooperative organization CORSICADA began. It aimed to not only give new life to traditional professions, but also to innovate in artisanal practice. It is home to a community of artisans and musicians and has been completely restored using ancient techniques. Long before "cultural tourism" and "protection of cultural heritage" entered everyday discourse, Pigna had already begun its revolution:

To survive, it was necessary to return the village to its prior dynamism.

Two potters moved in in the late 60s, then a sculptor and flute maker. The old presbytery was converted into housing for artisans. The houses brushed the dust off their orange roofing tiles and their shutters traded their worn-out brown for a sky blue. The village was founded in $862 \mathrm{AD}$. The little streets are narrow, bordered by typical Corsican houses. Today, Pigna illustrates the success that can come from daring to beat the odds by bringing together modernity and authenticity; new technologies and history. In summer, more than 700 visitors lose themselves daily in the paved streets....(Mairie de Pigna 2017).

In this text, we see how the recent history of the village and its participation in cooperative and cultural movements is represented as a critical part of its contemporary identity. Visitors to the website are thus urged to view the village's current vitality as the outcome of an intentional process that needs to be remembered, and which includes a strong emphasis on integrating tradition and modernity/innovation and on the agency of local social actors. Pigna today is represented as a successful culmination of social and cultural action. In the following sections, we will take a close look at the semiotic practices that are vehicles and signs of that action and how they position Pigna in a wider poetic economy.

\section{The poeticization of the economy}

\subsection{Multiscalar positioning and the central periphery}

We turn now to some of the practices that poeticize the economy and link the hyper-local with the supra-local, or "global cool" (Kelly-Holmes 2005). One 
place where this is evident is in the music scene (see also Leone-Pizzighella, this Issue). Consider the following small sample of the texts of concert posters for events in Pigna. I have translated the full text of the language on each poster:

1. Tchavolo Schmitt: La légende du jazz Manouche 'Tchavolo Schmitt: Gypsy Jazz Legend'

2. "Nos voix dessinent le même paysage": concert, création autour des polyphonies corses et georgiennes 'Our voices draw the same landscape: concert, creation around Corsican and Georgian polyphony'

3. “A Cumpagnia”-Polyphonic music from Corsica

The first concert represents Pigna's participation in the progressive/hip international World Music scene. The second shows them forging creative linkages and collaborations between Corsican polyphonic traditions and practitioners of polyphonic singing from other parts of the world. The third advertises a group based in Pigna and founded by Casalonga's brother Jérôme.

These musical events take place in an auditorium that itself speaks to Pigna's successful bid for regional, national and European funds. This structure, which seats over 200 people, is dramatically disproportionate to the size of the village (under 100 permanent residents). It represents Casalonga's success as a European social/artistic actor. It is also emblematic of how Pigna has reframed notions of "center" and "periphery" (Pietikäinen and Kelly-Holmes 2013). On the one hand, it is a village-associated in Corsica with the interior of the island, which is peripheral with respect to the central tourist destinations which are cities and beaches. However, it is located only $7 \mathrm{~km}$ from the small coastal city of IleRousse, so it is within easy access to the tourists who flock there. And they do, because Pigna has also become a must-see cultural destination in tourist guide books on Corsican since the 1980s. As the village website mentions, in the height of the summer season, the village can receive over 700 visitors per day, a number which strains the (pay) parking lot and other capacities for accommodating tourists. But the auditorium-and the concerts it hosts, along with the Archive of Traditional Music (VOCE) in the village situates Pigna as a center of traditional musical research and practice-thus as not peripheral at all to the cultural life of the island.

\subsection{Esthetic coordination and language}

Pigna has also cultivated a very careful, self-conscious and coherent visual esthetic in which the Corsican language plays a significant role. The entrance to the village announces that it is a pedestrian zone, and also that it is "green" $-\mathrm{CO}-2$ 
free. The esthetic is most visible in signage, including personal or private signs on houses showing who lives there. All of the street, business and place names are in Corsican. The font, while not semiotically coded as "traditionally Corsican" in the way that Irish Gaelic lettering is, for example, is recognizably hip, rustic and artsy (see Figure 1 below). It is not just a style, but also stylized, which draws attention to the agency of the artists/authors. That agency and intentionality is also foregrounded by the very consistency of the signage, which bespeaks a coordinated choice by all the social actors in the village.
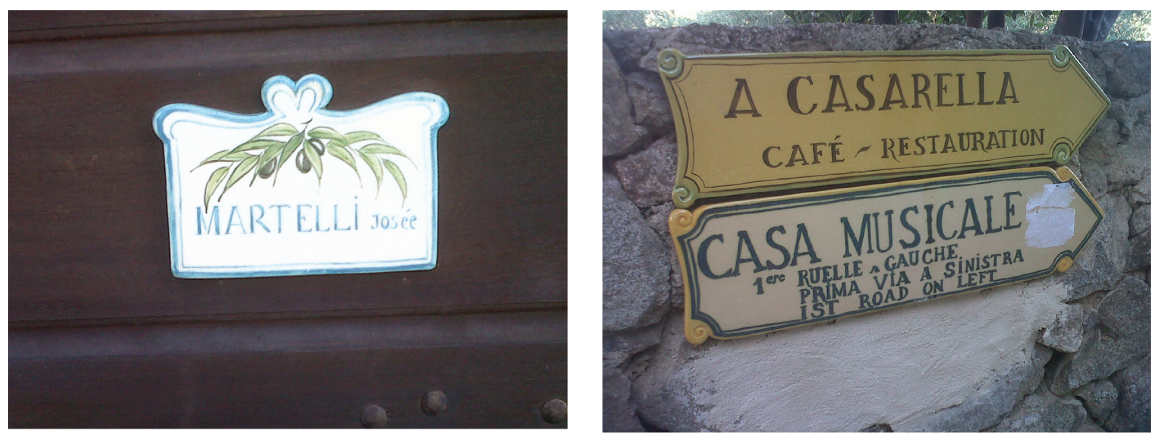

Figure 1: Stylized lettering on private home and commercial signage.

\section{A Casarella 'The Little House' Corsican \\ Café-Restauration 'Café-Food' French}

In addition to the signature font of all professionally produced ceramic and wooden street and house signs (all created by one of the potters in the village), other hand-painted or written signage reflects a similar, rustic esthetic. We see this in Figure 2, which shows advertising for rooms for rent in a house (in the left-hand photo) and, on the right, a variety of signs outside the small restaurant Casa Savarelli which are written on wood, chalkboard, and stone and also include a framed sign advertising the foods and drinks they serve. These scriptural practices - irregular and imperfect handwriting-index the individuality of the writer/owner. This individuation stands in implicit contrast with massproduced, alienable, impersonal products and services and thereby, proffers an "authentic," personalized, intimate commercial relationship (Coupland 2003; Pietikäinen et al. 2016). It also indexes "lack of artifice," or "naturalness" often taken as a sign of authenticity (Coupland 2003; Bucholtz 2003; Pietikäinen et al. 2016). Thus, these signs navigate a delicate path between what Bucholtz calls "naturalized" and "denaturalized" usage; between drawing attention or 

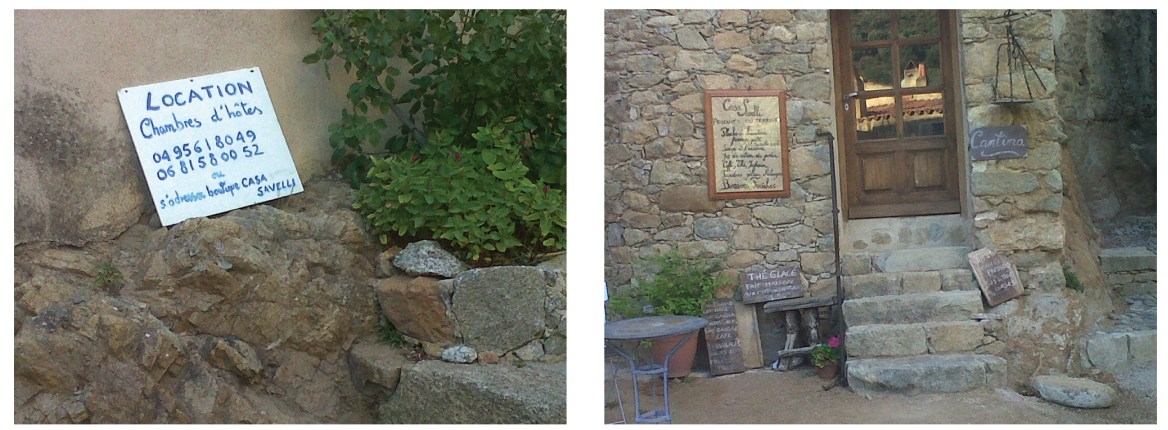

Figure 2: Individually hand-painted signs.

obscuring the social conditions of production (see Bucholtz 2000). The semiotic ideologies underpinning these sign complexes parallel competing language ideologies in the defense and promotion of Corsican, where essential, traditional and "natural" use of Corsican as a "Mother Tongue" comes into tension with intentional, stylized uses of Corsican as a "Lingua Matria" (CCECV 1989).

With respect to the position of Corsican in Pigna's signage, it holds a clear place of honor as the language of all proper names-whether street or business names. For example, one street sign reads (in Corsican) "Stretta di Zia Nene" (Auntie Nene's Little Alley); another is labeled "Chjassu à l'Insettu" (Insect Alley). Those proper names are also infused with intimacy: the intimacy of the figure of the aunt (enhanced by the fact that "Nene" is a diminutive) and the whimsical name of "Insect Alley," which suggests a meaningful, historical, highly local origin story.

Overall, then, the public face of the village offers it up as an intimate product for public consumption. A little square accessible through a small door is labeled "the garden" in Corsican - as opposed to a "park" - you, the visitor, are invited in (Figure 3).

Small stores and artisans' workshops are located in the village in the same architectural spaces as people's homes, and are often stylized as intimate kinds of interiors. This is illustrated in Figure 4, which shows a photo of the inside of a Corsican food products store on the right and on the left, a picture I took inside an open residential door.

At the same time, the use of Corsican is integrated into a communicative whole in signs pointing to businesses or on their exteriors where its use is flagged as primarily symbolic. This is because it is other languages-French, English and Italian, or words that can be considered international rather than English-are used to convey propositional content. 

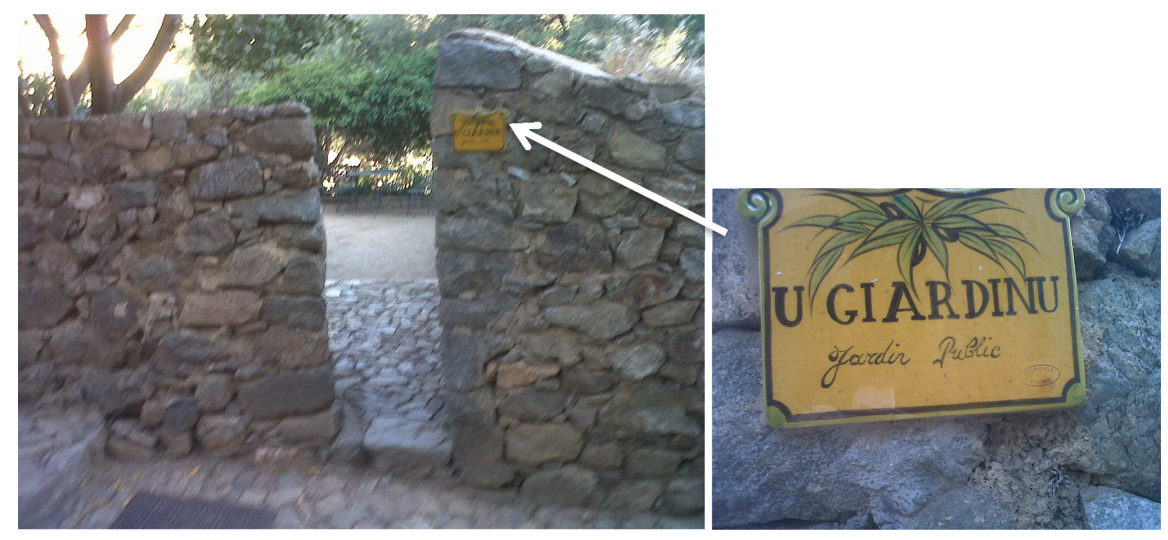

Figure 3: U Giardinu.
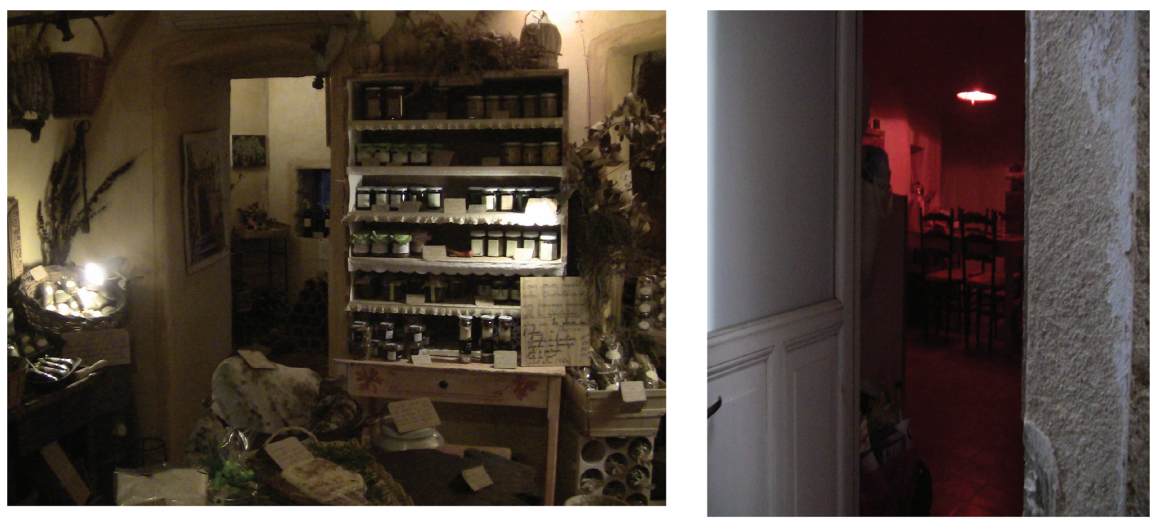

Figure 4: Intimate interiors, both commercial and private.

Figure 5 displays the intentional stylization of the village visual esthetic embodied in the blue shutters and doors. As the village website indicates, this was not their historical color (which was a "dull brown"); nor are blue doors and shutters a traditional element of any other village on the island. Like the ceramic place signs, these colors are too consistent to be random, and display collective esthetic coordination. They have become a consistent element in tourist guide descriptions of the village. The Lonely Planet Guide writes: "Particularly charming is Pigna, a mirage of burnt-orange rooftops and blue-shuttered houses $8 \mathrm{~km}$ south of Île Rousse via the D151" (Lonely Planet 2017) and the French site Le Bon Tourism tells prospective visitors, "Your feet will lead you down the length of 

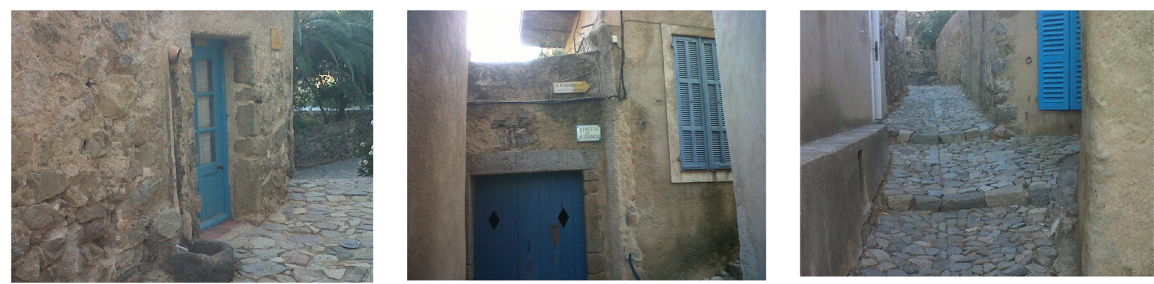

Figure 5: Blue doors and shutters.

narrow alleyways, bordered with houses with their sky-blue shutters, towards the old presbytery converted into artist lodgings.” (Bon Tourism 2017).

Overall, then, we can argue that Corsican is given a significant symbolic role in a coordinated semiotic complex of signs and colors (see Perrino, this Issue), but is neither privileged over other forms of representation nor proposed as a replacement for languages of wider communication (French, Italian and English). Within traditional models of language revitalization, emblematic uses of the minority languages are understood to be fulfilling identity functions, but are not considered serious initiatives relative to the goal also of reversing language shift and creating more speakers and more conversational use. While the signs in Pigna are indeed emblematic, the fact that they are embedded in coordinated semiotic esthetic shifts the focus away from traditional language revitalization goals and locates collective agency not so much in shared, proficient use of the minority language but in shared, proficient use of the minority language as a powerful element in a representational program that involves multiple cultural resources and multiple media.

\subsection{Soundscaping tourist trajectories}

We turn here to a project that was piloted during Pigna's 2012 Estivoce summer music festival and culminated with a regional iPhone app in 2015. Called E Petre Chì Cantenu 'The Rocks that Sing', this project involved placing small posters with QR codes in four strategic locations in the village: the fountain, the church, the auditorium, and an open-air auditorium. This use of cutting edge technology (so new that many smartphone users did not know how to access the application needed to read the QR codes) was another example of the integration of tradition and modernity in Pigna.

The signs had a brief explanation of their function in French, Corsican, Italian and German. The QR codes sent users directly to a webpage where a 
sound file with some traditional form of music or poetry was launched. Written texts in French and Corsican explained the location (e.g., the history of the fountain), the song genre, and its connection with place. The project website had the following explanatory text written in French. ${ }^{1}$ :

- This project is an example of a recognized scientific research process: the preservation of intangible heritage.

- But in addition, in order to provide our work to the maximum number of people, we hope to make it possible to disseminate these materials in an appropriate way in context, in the very places that are sung about in traditional music and in connection with the activities that used to take place in those sites. This is the goal of the current project; whose ambition is to blend intangible and material heritage.

- Ultimately, the plan is to develop maps of the territory that show all of the places that have been put to voice in the Balagne region that can be turned into one or several heritage itineraries for tourists. A sound route is thus envisioned along the model of the "Route of the Artisans" or the "Wine Route". It will allow people to easily follow a thread, across the landscape, from a paghjella (polyphonic song) to a chjama è rispondi ('call and response' a type of improvised poetry). This additional way of structuring the rural territory will allow the local, sustainable implantation of new ways to visit the Balagne: all through music.

We can note first that this text adopts UNESCO terminology of "tangible" and "intangible" heritage and makes reference to scientific practice (UNESCO 2017a, UNESCO 2017b). In doing so, Pigna indexes international scales of practice and value, and stakes a claim that complements its World Music stance: to be a savvy, global player in the process of knowledge production capable of innovation in the blending of tangible (material) and intangible (immaterial) culture. Further references to the global discourse of sustainability support this discursive effort. The text lays out a program of making place in a way that links current to historical experience and practice using cutting edge technology: again, integrating tradition and modernity. The program also involves shaping tourists' trajectories across space by leading them from one musical and material place to another. Below is an example of the web text that could be accessed by capturing the $\mathrm{QR}$ code at the fountain. The website also included a recording of the song named below:

Why these archives here? What you are listening to right now is:

1 This and all translations of original texts into English are my own. 
“Take my bucket....” recorded by Nicole Casalonga and Toni Moscardini, August 1980. This very well-known song recounts in dialog form (a "cuntrastu") the lovers' dispute of a couple on the path to the fountain, which begins badly but ends up well. The author is believed to be Désiré Morastoni of Galeria. It was recorded during a concert of A CUMPAGNIA in the Casazza of Calenzana.

This text establishes links between three time scales: the distant past in which the song was first written and in which lovers still met at the fountain; the recent past in which members of the Corsican cultural renaissance recorded the historical song and the present in which the visitor to the fountain accessed the recording through the flash code (see Leone-Pizzighella, Perrino, this Issue). Both past timescales are connected to named, specific places and people: the original author from Galeria, the two singers from Pigna, the group A Cumpagnia from Pigna and the place of the recording event: an event hall (Casazza) in the nearby town of Calenzana. This enumeration of people and places, and the reference to the movements of the singers, circumscribes and inscribes the Balagne region as a territory and thus proposes that territory as an authentic visitable to the person accessing the song. It also subtly authenticates the managers of the Pigna music archives as mediators of authenticity for listeners/visitors. That is, the song linked to the fountain is not a song from Pigna, nor is that particular fountain identified as the historical place where the song was sung. Rather, it is a token of a type of song sung in a type of place: the visitor entrusts this semiotic linking to the archivist.

The use of the flash codes in this project to scaffold a tourist's trajectory through the village via Corsican music was new and experimental, but it was also consistent with an event called the Granitula that took place almost every year at Estivoce, the summer music festival. This festival ties into the World Music thematic of the village, as illustrated by the text on the Corsican Tourist Board's website for the event:

Each year in July in and around Pigna, the heart of the festival, the most beautiful villages of the Balagne welcome the different concerts of ESTIVOCE, where the voices of the world rub shoulders with those of Corsica and accompany theater or dance. This is the festival of the voice across different time periods and different musical genres, leading and mixing together artists and spectators in the discovery of this beautiful magnificent region, sowing the seeds of future creativity in between rocks that are filled with history. As the summer nights unfold, music from Corsica and voices from here and elsewhere will be raised in the discovery of Roman chapels or in rich Baroque churches, across the gardens, little streets and vaults of Pigna, in the heart of the "Vaccaghja," former cattle pen turned into an openair theater (Corsican Tourist Bureau 2013).

The Granitula takes place on the big, closing event of the festival. Granitula literally means snail, and is also used to describe the spiral movement of some 
Corsican religious processions. In the 2012 version of the event that I attended, the many paying visitors to the festival were milling about on the main square in front of the church when a voice, singing in Corsican, rung out into the evening air from an open window in the second floor of a house just to their left and moving inwards on the village streets. As people moved towards this hidden voice, it ceased and another singer appeared on a stone balcony that bridged houses on either side of an adjacent, narrow street. The crowd, now constituting a loose processional, moved together towards this second voice, to be further led into the village by another pair of voices inside an open door. The growing procession gradually went up and into the village, ending up on a square at the top of the village just as the sun set, where they encountered an entire musical group in full performance and could look out over the spectacular valley leading to the sea.

Like the sustained, coordinated signage, the Granitula structured tourists' experiences of the village, this time, through an embodied experience of Corsican language and song. Two years later, the Petre Chi Cantenu experience was transformed into a regional Android/iPhone application called A Strada Musicale, 'The Musical Path.'

The tourist agency of the Balagne region presents the application on its website with the text below:

The application A Strada Musicale 'The Musical Route' is a genuine immersion in the heart of a spoken and sung heritage, root of the island's culture. Conceived of as a traveling audio guide, it will accompany you in the very places where these acoustic practices took place: canti sacri 'sacred songs' in churches, tribbiere 'threshing songs' on the aghje 'threshing fields'...It is linked to 90 indexed sites identified by special signage which link to its own specific sound file and explanation. The application will notify you immediately when you are near a listed site (all boldface in original). Spanning all of the villages of the Balagne (Balagne Tourist Office 2017), A Strada Musicale is also a unique way to discover the beauty and charm of the back-country where Corsican hospitality is far from being a myth.

In this text, we see the discourse of $E$ Petre Chì Cantenu redeployed at the regional level, where villages like Pigna are identified as authentic "back-country" or interiors where authentic Corsican hospitality is practiced. Corsican terms/ names, including the name of the app itself are bolded and translated on this website, cementing their cultural significance as markers of place and vessels of culture. Like the Petre Chi Cantenu project, the Strada Musicale application maps out a territory-users can view all the sites on a map and aim their trajectories towards them. It also adds the push-factor: as users walk or drive by sites that they may not have specifically targeted, the application notifies them that they are near a sign/site. For the user of the app, there are no neutral, culturally void 
landscapes; he or she is voluntarily engaged on a full-time basis with a soundscaped territory that includes Corsican as part of the acoustic heritage at the heart of Corsican culture.

\section{Tensions and contestation: The economization of poetry}

As we have seen, Pigna is a village where social actors exercise a great deal of control over a discourse in which tourism is represented as a harmonious form of intercultural exchange in a poetic economy. The soundscaping of place, with Corsican music and bilingual texts, creates trajectories whose value is also a point of positive exchange between and for locals and tourists.

At the same time, this discourse does not exist without points of tension and contestation. The first has to do with control over representations and their consequences. In my conversation with the Pigna archivist about the development of the Petre Chì Cantenu project, she worried about overdetermining tourists' experiences of place and in general, about excess semiotization of landscapes. In part, this was a concern about the audience or consumer's experience, but it was also about the experiences of those living in the soundscaped places - she was not sure if village inhabitants wanted to feel as though they were in a living museum. I asked her if that wasn't what it was already like to live in Pigna, and she said yes, it was very difficult in the summer months. Switching from a museum to a zoo metaphor, she likened village residents to monkeys that tourists threw peanuts at. So, there is a tension between public and private, a feeling of loss of control over space due to the volume of tourists. This tension is vividly illustrated by a hand-lettered wood sign reading "Jardin Privé” (Private Garden) placed by a property owner on a metal. In sharp contradistinction to the stylized sign " $U$ Giardinu" of Figure 3 that designated a space as "visitable" in Corsican, this unstylized French-language sign is designed to keep people out. So, we can see two things: 1) Corsican has been recontextualized in Pigna from a private language to one that is used emblematically, to designate a public, touristic sphere. French is used as the voice of the private citizen and the language of wider communication through which that citizen lets the tourist know that there are boundaries between the front and back stage in this village, that real and private life is going on and they are not invited in. This need for boundary maintenance was highlighted in several accounts I heard of tourists occasionally walking right through an open door into someone's kitchen. 
Another tension that was reported to me by the University intern working in the village's tourist welcome center also has to do with the access and intimacy that are linked to a poetic economy. That is, the village's successful marketing as a site of artisanal production has created a frame for the consumption of authenticity by tourists. They expect to be able to have access to both the site and moment of production of goods, so they want to visit the artisans' workshops to see them making their goods. However, many of these artisans do most of their work in the off-season. Their workshops are small, and they are reluctant to have people crowding in. They are also not at all convinced that allowing this intimate access and inviting more interaction will lead to more sales. In fact, they report that over the last few years, the volume of visits has stayed the same, but sales have fallen off, a fact they attribute to "economic crisis" - that people just have less money. As a consequence, they view workshop visitors as much more likely to consume their images by taking pictures of their quaint locales than to purchase goods.

The welcome center intern told me a story that illustrated how this dynamic affected Pigna shopkeepers' responses to tourist inquiries. She had taken a phone call from a Porsche Club that was touring the region and wanted to know if they could get a village tour at 9 am, before most stores and workshops typically open. The intern called several store owners to see if they would open up for the group. Those owners would not commit until she confirmed that the group was composed not of senior citizens in a bus, but of prosperous middle-aged drivers of luxury cars. While this is related to what Heller et al. (2014) characterize as "inevitable tensions" between commodification and authenticity, it is also a form of resistance to the forced intimacies of forms of cultural tourism.

\section{Conclusion}

Corsican language revitalization has historically been confined to official and institutional contexts, with an emphasis on harnessing the authority of policy and educational practice to redress the unequal relationship between Corsican and French. Within this effort, linguistic authenticity at both the personal and collective levels was conceptualized in a "pride" framework where language and identity were conceptualized in essentializing, and the goals of language advocacy understood as recreating historical, natural use of Corsican as a "Mother Tongue." This corresponds to what Pietikäinen et al. (2016: Chapter 3) have characterized as "conventional" authenticities. In the case of Pigna, we see evidence of these conventional authenticities in multiple references to 
traditional architectural, musical and artisanal practices and the goal of returning the village to its previous vitality. We also see the deployment of emblematic uses of Corsican as added authenticity value in a tourist market ("profit," in Duchêne and Heller's terms). At the same time, Pigna displays an orientation to more transactional authenticities that do not take the value of any particular form for granted, and validate performance and verisimilitude as forms of cultural production with a legitimacy that is tied to the intentions of producers and willing reception by consumers. Thus, we have seen cultural actors deploy traditional linguistic and musical forms in non-traditional ways, including the use of Corsican for almost exclusively symbolic and emblematic purposes that acknowledge advanced language shift towards French and locate authenticity in agentive action and intentions rather than in linguistic form. This represents a logical outcome of the framework of the "Lingua Matria," where the collective endorsement of language as heritage is the glue that holds the Corsican people together. With respect to frames for minority language valuation, the Pigna case shows that one of the shifts of the contemporary era is not just a movement away from "pride" towards "profit," but also a redefinition of the role of language-as-practice in the collective imagination of how language is implicated in heritage.

We also see an explicit orientation to both the integration of tradition and modernity, the local and the supralocal. More implicitly, we see evidence of these categories-as well as center and periphery being rearticulated as relative rather than fixed through the invocation of multiple, simultaneous scales (as in the timescales involved in the online texts at the fountain).

With respect to profit, Pigna also illustrates some shifts in the nature of minority language promotion that can occur when the promotion of the language is taken out of official and institutional contexts and integrated into a poetic (and commercial) economy. Here, it is not a straightforward case of Corsican being used as added value to a non-linguistic product, or of Corsican authenticating products or place-though both of these things are certainly going on. What seems more interesting in the Pigna case is how Corsican, while attributed significant symbolic value, is not fetishized but rather, is integrated as just one part of a larger process of semiotic landscaping (Jaworski and Thurlow 2010) that includes scripts, surfaces, colors and sound/ music that are both stylized and tightly orchestrated. This draws attention to acts of stylization as forms of cultural agency rather than focusing, as much language revitalization does, solely on language as an index of cultural authenticity or on language as an autonomous code.

Those semiotic complexes are heavily implicated in the making of place (at both village and regional levels) and in the guiding of tourist trajectories from 
one place to another. These processes of authentication are bidirectional: the emplacement of QR codes in Pigna and across the region authenticates places on the ground that in turn, link types to tokens and authenticate the social actors at the Pigna music archives and others who participated in the development of the Strada Musicale app and online content in the Balagne region.

Finally, we have seen that the staging of language and other esthetic forms and the staging of tourist encounters (as in the Granitula) raise issues of participant structures, boundaries, agency and intimacy. A tourism of cultural intimacy can create shared trajectories and shared sites of encounter for locals and tourists. The Strada Musicale application is not just for tourists-it's also for locals. The Granitula involves tourists and performers in a shared, embodied experience of place and sound. But it can also blur the boundaries between the public and the private in ways that challenge locals' control over processes of authentication that are increasingly complicated in a world where the local and the peripheral are complexified by global processes and frameworks. When that happens, as we have seen, the locals slap up a sign in French that draws a clear, unpoetic line.

Guest Editors' Note: This article was in the final stages of the editing process when the very sad news of Alexandra Jaffe's death reached us. Aside from a handful of very small copy-editing matters for which approval was pending (and which we have silently resolved), it appears here in the form she approved for publication. We join many of our colleagues in feeling bereft of the inspiration, collegiality, and leadership that Alexandra Jaffe generously provided throughout her career. All of the articles housed in this Special Issue benefited greatly from her commentary during the original conference panel where the papers were first presented. While being extremely saddened, we feel very honored to have Alexandra Jaffe's article in our Special Issue.

(Sabina Perrino \& Andrea Leone-Pizzighella, as Guest Editors of Multilingua, Vol. 38, Issue 1, 2019)

\section{References}

Antonmarchi, Florence, Toni Casalonga, Charlie Galibert, Franck Michel, \& Jean-Didier Urbain. 2010. Imaginaire, île, tourisme, Corse: Voyage à plusieurs voix. Autres Voies 6. http:// www.deroutes.com/AV6/num6.htm (accessed 10 December 2011).

Bakhtin, Mikhail. 1992. The dialogic imagination: Four essays. Austin: University of Texas Press. 
Balagne Tourist Office. 2017. A strada musicale. http://www.balagne-corsica.com/a-stradamusicale.html (accessed 5 November 2017).

Bauman, Richard, \& Charles Briggs. 1990. Poetics and performance as critical perspectives on language and social life. Annual Review of Anthropology 19. 59-88.

Beacco, Jean-Claude, \& Michael Byram. 2003. Guide for the development of language education policies in Europe, main version, draft 1 (revised) April 2003. https://www.coe.int/t/dg4/ linguistic/Source/FullGuide_EN.pdf (accessed 11 November 2017).

Bon Tourism. 2017. Pigna in Corsica. http://www.bontourism.com/it/content/pigna-in-corsica (accessed 5 November 2017).

Bucholtz, Mary. 2000. The politics of transcription. Journal of Pragmatics 32. 1439-1465.

Bucholtz, Mary. 2003. Sociolinguistic nostalgia and the authentication of identity. Journal of Sociolinguistics 7. 398-416.

CCECV (Conseil de la Culture, de l'Education et du Cadre de Vie). 1989. Cultura : Essai sur l'approche d'une politique culturelle. Assemblé de Corse.

Corsica Tourist Bureau. 2013 http://www.visit-corsica.com/fr/Actualites/ESTIVOCE (accessed 5 July 2014).

Council of Europe. 2001. Common European framework of reference for languages. https://www. coe.int/t/dg4/linguistic/source/framework_en.pdf (accessed 11 November 2017).

Coupland, Nikolas. 2003. Sociolinguistic authenticities. Journal of Sociolinguistics 7(3). 417-431.

Heller, Monica, \& Alexandre Duchêne. 2012. Pride and profit: Changing discourses of language, capital and nation-state. In A. Duchêne and M. Heller (eds.), Language in late capitalism: Pride and profit, 1-21. New York \& London: Routledge.

Heller, Monica, Adam Jaworski, \& Crispin Thurlow. 2014. Introduction: Sociolinguistics and tourism - Mobilities, markets, multilingualism. Journal of Sociolinguistics 18(4). 425-458.

Jaffe, Alexandra. 2007. Minority language movements. In M. Heller (ed.), Bilingualism: A social approach, 50-70. Basingstoke \& New York: Palgrave MacMillan.

Jaffe, Alexandra. 2011. Sociolinguistic diversity in mainstream media: Authenticity, authority and processes of mediation and mediatization. Language and Politics 10(4). 562-586.

Jaffe, Alexandra, Michèle Koven, Sabina Perrino, \& Cécile Vigouroux. 2015. Introduction: Heteroglossia, performance, power and participation. Language in Society 44. 135-139.

Jaworski, Adam, \& Crispin Thurlow (eds.). 2010. Semiotic landscapes: Language, image, space. London \& New York: Continuum.

Johnstone, Barbara. 2010. Language and place. In R. Mesthrie (ed.), Cambridge handbook of sociolinguistics, 203-217. Cambridge: Cambridge University Press.

Kelly-Holmes, Helen. 2005. Advertising as multilingual communication. Basingstoke \& New York: Palgrave MacMillan.

Kelly-Holmes, Helen. 2014. Linguistic fetish: The sociolinguistics of visual multilingualism. In D. Machin (ed.), Visual communication, 135-152. Berlin: De Gruyter.

Lonely Planet. 2017. Welcome to the balangne interior. https://www.lonelyplanet.com/france/ corsica/la-balagne-interior\#introduction (accessed 3 November 2017).

Mairie de Pigna. 2017. Le terreau culturel et artisanal de la Balagne. http://www.pigna.fr (accessed 3 November 2017).

Pietikäinen, Sari, \& Helen Kelly-Holmes. 2011. The local political economy of languages in a Sámi tourism destination: Authenticity and mobility in the labelling of souvenirs. Journal of Sociolinguistics 15(3). 23-346.

Pietikäinen, Sari, \& Helen Kelly-Holmes (eds.). 2013. Multilingualism and the periphery. Oxford \& New York: Oxford University Press. 
Pietikäinen, Sari, Helen Kelly-Holmes, Alexandra Jaffe, \& Nikolas Coupland. 2016.

Sociolinguistics from the periphery: Small languages in new circumstances. Cambridge: Cambridge University Press.

Silverstein, Michael, \& Greg Urban (eds.). 1996. Natural histories of discourse. Chicago: University of Chicago Press.

Thurlow, Crispin, \& Adam Jaworski. 2010. Tourism discourse: The language of global mobility. Basingstoke: Palgrave MacMillan.

UNESCO. 2017a. Tangible cultural heritage. http://www.unesco.org/new/en/cairo/culture/tan gible-cultural-heritage/. (accessed 11 November 2017.

UNESCO. 2017b. Intangible cultural heritage. http://www.unesco.org/new/en/cairo/culture/ intangible-cultural-heritage/. (accessed 11 November 2017). 